\title{
The results of 2013 survey to evaluate laparoscopic and robotic partial nephrectomy practice in the United Kingdom
}

\author{
Nikhil Vasdev 1,2 , Sebastian Mafeld 2, Oliver Fuge 1, Timothy Lane 1, Gregory Boustead 1, \\ James M Adshead 1, Naeem A Soomro ${ }^{2}$ \\ ${ }^{I}$ Department of Urology, Hertfordshire and South Bedfordshire Robotic Urological Cancer Centre, Lister Hospital, Stevenage, UK. \\ ${ }^{2}$ Department of Urology, Freeman Hospital, Newcastle upon Tyne, UK.
}

Received February 02, 2014; Revised March 12, 2014; Accepted March 15, 2014; Published Online March 25, 2014

\section{Editorial}

With the increase of routine ultrasound and cross-sectional imaging there has been an increase in the number of small renal masses worldwide. ${ }^{1,5}$ Due to this trend there is migration on the diagnosis of smaller renal masses that localized lesions, which has allowed for urologists to pursue nephron-sparing approaches to treatment, including partial nephrectomy and targeted in situ ablation. ${ }^{2}$ Laparoscopic partial nephrectomy (LPN) similarly offers equivalent disease-specific outcomes but with shortened convalescence compared with OPN. ${ }^{3}$

However, LPN is a technically challenging procedure that requires advanced laparoscopic skills and, in the vast majority of cases, the need for renal hilar occlusion. ${ }^{4,5,7}$ In an attempt to shorten the considerable learning curve associated with LPN, to ease surgeon fatigue, and to further expand indications set for LPN, robotic partial nephrectomy (RPN) has been introduced. Outcomes of early experience reports have thus far have been favourable..$^{5,6}$

In the UK there is a variation in the number of LPN and RPN being performed throughout the country. To establish current practice of either technique we developed a questionnaire, which was sent to all Urological cancer units in the UK in March 2013 with a request of all participating urological surgeons to return the survey within 3 months of receipt. Prior to sending the questionnaire each cancer centre was individually telephone by both the first and second authors of this paper. A $73 \%$ response was received from

Corresponding author: Nikhil Vasdev, FRCS (Urology); National Robotic Urological Fellow, Hertfordshire and South Bedfordshire Robotic Urological Cancer Centre, Lister Hospital, Stevenage, UK. Email: nikhilvasdev@doctors.org.uk

Cite this article as:

Vasdev N, Mafeld S, Fuge O, Lane T, Boustead G, Adshead JM, Soomro NA. The results of 2013 survey to evaluate laparoscopic and partial nephrectomy practice in the United Kingdom. Int J Cancer Ther Oncol 2014; 2(2):02022. DOI: 10.14319/ijcto.0202.2 national experts in the UK performing either LPN (Group 1) or RPN (Group 2). All data collected included selection criteria, pre-operative scoring, details of surgical technique, average warm ischemia time and approximate complication rate.

The results of the survey indicated that surgeons in Group 1 (LPN) consisted of 19 Surgeons who have performed a total of 465 LPN from June 2002 until November 2012. All surgeons select tumour $<4 \mathrm{~cm}$ in size which are at least $50 \%$ exophytic. Ten percent of surgeons use the RENAL scorings system. The control of the renal hilum was with the lap bulldog (50\%), lap satinsky (20\%), rummell loop (10\%) and no clamp (10\%). The mean warm ischemia time was 16.6 minutes (Range 0 - 30). The mean incidence of urinoma was $2.4 \%$ (Range 2-15), AV Fistula $0.6 \%$ (Range 0 - 3) and emergency nephrectomy was $0.5 \%(0-4)$. Twenty percent of surgeons perform Retroperitoneal LPN.

In Group 2 (RPN) there were only 7 surgeons which indicates that RPN is only being performed by a select few centres in the UK and is a relatively new procedure who have performed a total of 227 RPN from January 2008 until November 2012. All surgeons selected tumour $<5 \mathrm{~cm}$ which were technically feasible. Fifty seven percent of surgeons use a scorings system i.e. RENAL or PADUA. The mean warm ischemia time was 15.3 minutes (Range 0 - 27). The control of the renal hilum was with the lap bulldog (100\%). The mean incidence of urinoma was 1 (Range 0 - 5), AV Fistula $0.5 \%$ (Range 0 - 5) and emergency nephrectomy was 0 . None of surgeons perform Retroperitoneal RPN.

The results of our questionnaire indicate that the number of RPN in the UK is increasing gradually and is associated with a comparable WIT to LPN. The numbers of centres performing RPN are few when compared to LPN, but the volume of cases per surgeon is higher than LPN. Only one sur- 
geon who participated in our survey performs retroperitoneal RPN.

In conclusion the results of our questionnaire indicate that $\mathrm{RPN}$ is a new technique in the UK which is being performed in a few select centres in the UK. The technique is being safely performed with only one surgeon performing the technique using the retroperitoneal approach. Early data indicates that the major complication rates of RPN cases are lower nationally in comparison to LPN. However longer follow up is required to validate these results.

\section{Conflict of interest}

The authors declare that they have no conflicts of interest. The authors alone are responsible for the content and writing of the paper.

\section{References}

1. Kunkle DA, Egleston BL, Uzzo RG. Excise, ablate, or observe: the small renal mass dilemma-a meta-analysis and review. J Urol 2008; 179: 1227-33.

2. Uzzo RG, Novick AC. Nephron sparing surgery for renal tumors: indications, techniques and outcomes. JUrol 2001; 166: 6-18.

3. Mabjeesh NJ, Avidor Y, Matzkin H. Emerging nephron sparing treatments for kidney tumors: a continuum of modalities from energy ablation to laparoscopic partial nephrectomy. J Urol 2004; 171: 553-60.

4. Fergany AF, Hafez KS, Novick AC. Long-term results of nephron sparing surgery for localized renal cell carcinoma: 10-year followup. J Urol 2000; 163 : 442-5.

5. Vasdev N, Giessing M, Zengini H, Adshead J, Rabenalt R. Robotic versus traditional laparoscopic partial nephrectomy: comparison of outcomes with a transition of techniques. J Robotic Surg Jan 2014.

6. Gill IS, Kavoussi LR, Lane BR, Blute ML, Babineau $\mathrm{D}$, et al. Comparison of 1,800 laparoscopic and open partial nephrectomies for single renal tumors. J Urol 2007; 78; 41-6.

7. Chan KE, Vasdev N. Current status of robotic training in the UK - a trainees perspective. Int J Cancer Ther Oncol 2014; 2:02013. 